\title{
A $\pi$-Stacked Porphyrin-Fullerene Electron Donor-Acceptor Conjugate That Features a Surprising Frozen Geometry
}

\author{
Alina Ciammaichella, ${ }^{[a]}$ Pavlo O. Dral,${ }^{[b]}$ Timothy Clark, ${ }^{[b]}$ Pietro Tagliatesta, ${ }^{*[a]}$ \\ Michael Sekita, ${ }^{[\mathrm{c}]}$ and Dirk M. Guldi ${ }^{*[c]}$
}

\begin{abstract}
A "frozen" electron donoracceptor array that bears porphyrin and fullerene units covalently linked through the ortho position of a phenyl ring and the nitrogen of a pyrrolidine ring, respectively, is reported. Electrochemical and photophysical features suggest that the chosen linkage supports both through-space and throughbond interactions. In particular, it has been found that the porphyrin singlet excited state decays within a few pico-
\end{abstract}

seconds by means of a photoinduced electron transfer to give the rapid formation of a long-lived charge-separated state. Density functional theory (DFT) calculations show HOMO and LUMO to be localized on the electron-

Keywords: density functional calculations - electron transfer • fullerenes $\cdot$ porphyrinoids $\cdot$ semiempirical calculations donating porphyrin and the electronaccepting fullerene moiety, respectively, at this level of theory. More specifically, semiempirical molecular orbital (MO) configuration interaction (CI) and unrestricted natural orbital (UNO)-CI methods shed light on the nature of the charge-transfer states and emphasize the importance of the close proximity of donor and acceptor for effective electron transfer.

\section{Introduction}

Photoinduced electron transfer (ET) in electron donor-acceptor conjugates has recently attracted much interest. A major goal of this research is to develop artificial photosynthetic systems that mimic the light-energy conversion processes of natural photosynthesis. ${ }^{[1]}$ The combination of porphyrins and fullerenes as donors and acceptors, respectively, has allowed the rates and efficiencies of charge separation to be maximized while simultaneously minimizing the rates of charge recombination (CR). ${ }^{[2]}$ Control over the electron donor-acceptor geometry has thereby evolved as the most versatile way to improve the efficiency of photoinduced electron transfer. Different geometries, such as porphyrin-

[a] Dr. A. Ciammaichella, Prof. Dr. P. Tagliatesta Dipartimento di Scienze e Tecnologie Chimiche University of Rome-Tor Vergata

Via della Ricerca Scientifica, 00133, Rome (Italy)

Fax: (+39)06-72594754

E-mail: pietro.tagliatesta@uniroma2.it

[b] P. O. Dral, Prof. Dr. T. Clark

Computer-Chemie-Centrum and

Interdisciplinary Center for Molecular Materials

Department of Chemie und Pharmazie

Friedrich-Alexander-Universität Erlangen-Nürnberg

Nägelsbachstrasse 25, 91052 Erlangen (Germany)

[c] M. Sekita, Prof. Dr. D. M. Guldi

Department of Chemistry and Pharmacy and

Interdisciplinary Center for Molecular Materials

Friedrich-Alexander-Universität Erlangen-Nürnberg

Egerlandstrasse 3, 91058 Erlangen (Germany)

Supporting information for this article is available on the WWW under http://dx.doi.org/10.1002/chem.201202245. fullerene cyclophane,${ }^{[3]}$ parachute, ${ }^{[4]}$ and pacman ${ }^{[5]}$ systems have been reported. Porphyrins and fullerenes are covalently linked in all these structures and adopt specific conformations that allow the $\pi$-electron systems to interact, even in the ground state. This has been attributed to strong van der Waals interactions between the two chromophores that are further augmented by Coulomb interactions in charge-transfer states. ${ }^{[6]}$ Note that "harpoon" folded charge-transfer conformations can also be formed from more extended groundstate geometries on excitation. ${ }^{[7]}$ Importantly, such folded conformations allow through-space interactions between the donor and acceptor moieties. Such through-space communications result in efficient and rapid deactivation of the porphyrin singlet excited state to give either fullerene excited states by energy transfer or the charge-separated state by electron transfer. These folded chargetransfer (CT) states are strongly stabilized by their stable Coulomb interactions compared to charge separation at longer distances.

The pacman structure is forced into this face-to-face alignment, which results in lower conformational freedom than found, for example, in the cyclophane and parachute geometries. Porphyrin-fullerene conjugates with more rigid geometries have also been reported in which the fullerenes are linked to the $\beta$-pyrrole position, ${ }^{[8]}$ directly to the meso position of the porphyrin ring, ${ }^{[9]}$ or through the benzene ring at the ortho position, as in the electron donor-acceptor conjugate 1 (Figure 1). ${ }^{[10]}$ Compound $\mathbf{1}$ differs from most other conjugates $^{[8,9]}$ because it contains a direct link between the carbon of the phenyl ring of the porphyrin and the pyrrolidine nitrogen of the fullerene, which gives rise to a completely frozen geometry similar to that found in cocrystallized porphyrin-fullerene systems. ${ }^{[6 a, 11]}$ In addition, the close 


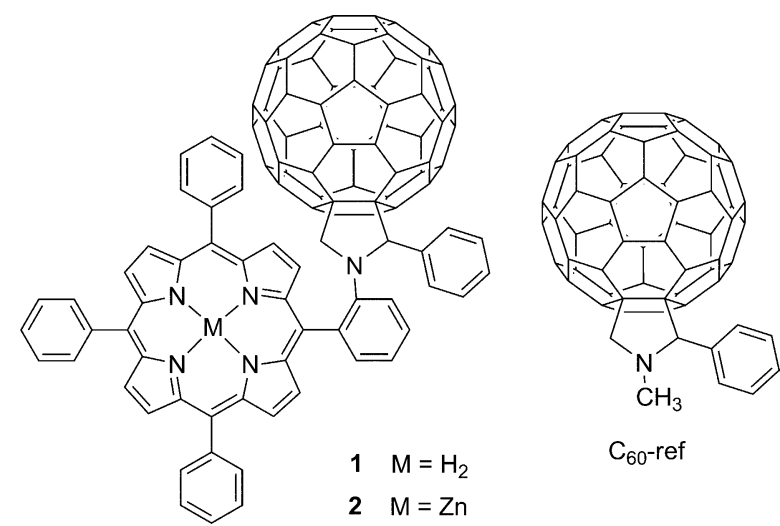

Figure 1. Porphyrin-fullerene conjugates $\mathbf{1}$ and $\mathbf{2}$ and the fullerene reference $\mathrm{C}_{60}$-ref.

proximity between the two chromophores results in considerable ground-state electronic interactions, as demonstrated by NMR and UV/Vis spectroscopy. ${ }^{[10]}$ A further advantage of $\mathbf{1}$ is that additional photo- and electroactive chromophores that bear an aldehyde functionality suitable for cycloaddition reactions to $\mathrm{C}_{60}$ can be introduced.

Here, we report electrochemical and photochemical studies on conjugate $\mathbf{1}$ and its zinc derivative $\mathbf{2}$ (Figure 1) with particular emphasis on the influence of the phenyl-pyrrolidine linker on the molecular properties. Cyclic voltammetry, absorption, fluorescence, and transient absorption measurements have been used to elucidate the energy- and/or electron-transfer reactions in polar and nonpolar solvents. Accompanying quantum mechanical calculations shed light on the influence of the structures and the electronic configurations of $\mathbf{1}$ and $\mathbf{2}$, especially on their charge-transfer properties.

\section{Results and Discussion}

Electrochemistry: Compounds $\mathbf{1}$ and $\mathbf{2}$ were characterized electrochemically by cyclic voltammetry. All measurements were carried out at room temperature in a $0.1 \mathrm{~m}$ solution of tetra- $n$-butylammonium hexafluorophosphate $\left(\mathrm{TBAPF}_{6}\right)$ in $o$-dichlorobenzene (o-DCB) with ferrocene as internal standard. The fullerene reference $\mathrm{C}_{60}$-ref (Figure 1) reveals three reduction steps at $-0.81,-1.18$, and $-1.71 \mathrm{~V}$ in the electrochemical window between -2.0 and $1.7 \mathrm{~V}$ (Table 1 ). The electrochemical behavior of the 5,10,15,20-tetraphenylporphyrin $\left(\mathrm{H}_{2} \mathrm{TPP}\right)$, which features two oxidation steps at 0.9 and $1.25 \mathrm{~V}$ and two reduction steps at -1.39 and $-1.67 \mathrm{~V}$, serves as an important reference point. The two reversible oxidation steps found in the cyclic voltammogram of $\mathbf{1}$ at 0.81 and $1.35 \mathrm{~V}$ are associated with the porphyrin. Importantly, these values are shifted relative to those of $\mathrm{H}_{2}$ TPP and suggest an intramolecular interaction between the two chromophores. Four reversible reduction steps are observed at $-0.74,-1.09,-1.27$, and $-1.62 \mathrm{~V}$. The $E_{1 / 2}$ values for the first and the second reduction potential corre-
Table 1. Half-wave potentials (V versus GCE) for the reduction and oxidation of $\mathbf{1}$ and $\mathbf{2}$ and their respective references in $o$-DCB containing $0.1 \mathrm{M} \mathrm{TBAPF}{ }_{6}$. All values are relative to a $\mathrm{Fc} / \mathrm{Fc}^{+}$internal reference.

\begin{tabular}{lllcccc}
\hline Compound & \multicolumn{2}{c}{ Oxidation } & \multicolumn{4}{c}{ Reduction } \\
& I & II & I & II & III & IV \\
\hline $\mathbf{1}$ & 0.81 & 1.35 & -0.74 & -1.09 & -1.27 & -1.62 \\
$\mathbf{2}$ & 0.74 & 1.1 & -0.81 & -1.17 & -1.55 & - \\
$\mathrm{H}_{2}$ TPP & $0.9^{\text {[a] }}$ & 1.25 & -1.39 & -1.67 & - & - \\
$\mathrm{ZnTPP}_{\text {nTP }}$ & 0.74 & 1.1 & -0.82 & -1.18 & - & - \\
$\mathrm{C}_{60}$-ref & - & - & -0.81 & -1.18 & -1.71 & - \\
\hline
\end{tabular}

[a] Irreversible processes.

spond to the formation of the fullerene mono- and dianion, whereas the third $E_{1 / 2}$ is close to the first reduction potential of $\mathrm{H}_{2}$ TPP. The last reduction step at $-1.62 \mathrm{~V}$ derives from the overlapping between the second porphyrin reduction and the third fullerene reduction. These potentials are also shifted relative to those of $\mathrm{H}_{2}$ TPP and $\mathrm{C}_{60}$-ref.

In general, the data for $\mathbf{2}$ are similar to those discussed for 1. In particular, the cyclic voltammogram of zinc(II) meso-tetraphenylporphyrin (ZnTPP) features two oxidation steps at 0.74 and $1.1 \mathrm{~V}$ and two reduction steps at -0.82 and $-1.18 \mathrm{~V}$. For $\mathbf{2}$, the two porphyrin-centered reversible oxidation steps are seen at 0.74 and $1.1 \mathrm{~V}$. The reversible reduction steps are centered at $-0.81,-1.17$, and $-1.55 \mathrm{~V}$. The first two processes feature overlaps of the first two reduction potentials of $\mathrm{ZnTPP}$ and $\mathrm{C}_{60}$-ref. The third reduction corresponds to the formation of fullerene trianion.

UV/Vis absorption spectroscopy: At first glance, the absorption spectrum of $\mathbf{2}$ in toluene is essentially a combination of the absorption spectra of ZnTPP and $\mathrm{C}_{60}$-ref (Figure 2). Closer examination reveals, however, that in toluene the Soret band of the porphyrin in 2 occurs at $430 \mathrm{~nm}$ and the $\mathrm{Q}$ bands at 553 and $592 \mathrm{~nm}$, whereas the Soret band in $\mathrm{ZnTPP}$ is found at $423 \mathrm{~nm}$. The molar extinction coefficient of the Soret band in $2\left(33.7 \times 10^{-4} \mathrm{M}^{-1} \mathrm{~cm}^{-1}\right)$ is lower than that for ZnTPP $\left(57.4 \times 10^{-4} \mathrm{M}^{-1} \mathrm{~cm}^{-1}\right)$. This is taken as strong evidence for through-space and/or through-bond interactions between the porphyrin and the fullerene. In more polar solvents such as THF and benzonitrile $(\mathrm{PhCN})$, the Soret band is red shifted by 1 and $6 \mathrm{~nm}$, respectively, relative to solutions in toluene (Figure 2). In addition, the molar extinction coefficients of the Soret band are also lower in more polar solvents than in toluene. This effect is due to a different solvation in the more polar environments. Similar trends evolve for $\mathbf{1}$ (Figure S1 of the Supporting Information) and are reported in Table 2.

Interestingly, in the near-infrared part of the spectrum, that is, between 600 and $800 \mathrm{~nm}$, low-intensity absorption bands were found for $\mathbf{1}$ and $\mathbf{2}$. On the basis of earlier reports, ${ }^{[10]}$ we attribute this band to a charge-transfer state due to ground-state interactions between the two chromophores. To better visualize the charge-transfer bands, the spectra of ZnTPP and $\mathrm{C}_{60}$-ref or $\mathrm{H}_{2}$ TPP and $\mathrm{C}_{60}$-ref were subtracted from those of $\mathbf{2}$ or $\mathbf{1}$, respectively. As shown in Figure 3, maxima evolve at $722 \mathrm{~nm}$ for $\mathbf{2}$ and at $716 \mathrm{~nm}$ for $\mathbf{1}^{[10]}$ 



Figure 2. Top: Absorption spectra of $\mathbf{2}$ in toluene (blue line), ZnTPP in toluene (red line), and $\mathrm{C}_{60}$-ref in toluene (green line). Bottom: Absorption spectra of 2 in toluene (blue line), THF (red line), and $\mathrm{PhCN}$ (green line).

Table 2. Soret bands of UV/Vis absorption spectra of $\mathbf{1}$ and $\mathbf{2}$ in toluene, THF, and benzonitrile ( $\mathrm{PhCN})$.

\begin{tabular}{lccc}
\hline Compound & \multicolumn{3}{c}{$\lambda_{\max }[\mathrm{nm}]\left(\varepsilon \times 10^{-4}\right)$} \\
& toluene & THF & PhCN \\
\hline $\mathbf{1}$ & $428(21.1)$ & $427(18.5)$ & $430(20.9)$ \\
$\mathbf{2}$ & $430(33.7)$ & $431(27.6)$ & $436(24.7)$ \\
\hline
\end{tabular}

Emission spectroscopy: The emission spectra of $\mathbf{1}$ and $\mathbf{2}$ were measured in toluene, THF, and PhCN. The excitation wavelength was $415 \mathrm{~nm}$ for $\mathbf{1}$ and $419 \mathrm{~nm}$ for 2. Figure 4 compares the emission spectra of $\mathbf{1}$ and $\mathrm{H}_{2}$ TPP in toluene. Compound 1 reveals two emission maxima centered at 653 and $718 \mathrm{~nm}$, whereas $\mathrm{H}_{2}$ TPP gives rise to two maxima at 652 and $716 \mathrm{~nm}$. The fluorescence quantum yield of $\mathbf{1}$ was calculated by the comparative method with $\mathrm{H}_{2}$ TPP $(\Phi=$ 0.11 ) as standard to be $1.9 \times 10^{-3}$ (Table 3 ). In more polar THF and PhCN, a solvent effect governs the fluorescence quenching. In particular, the quantum yields decrease upon going from the less polar toluene $\left(\Phi=1.9 \times 10^{-3}\right)$ to the more polar $\mathrm{PhCN}\left(\Phi=9.6 \times 10^{-4}\right)$. A similar trend was found for 2 relative to ZnTPP. Here, the emission maxima of 2 were found at 596 and $644 \mathrm{~nm}$, and those of ZnTPP
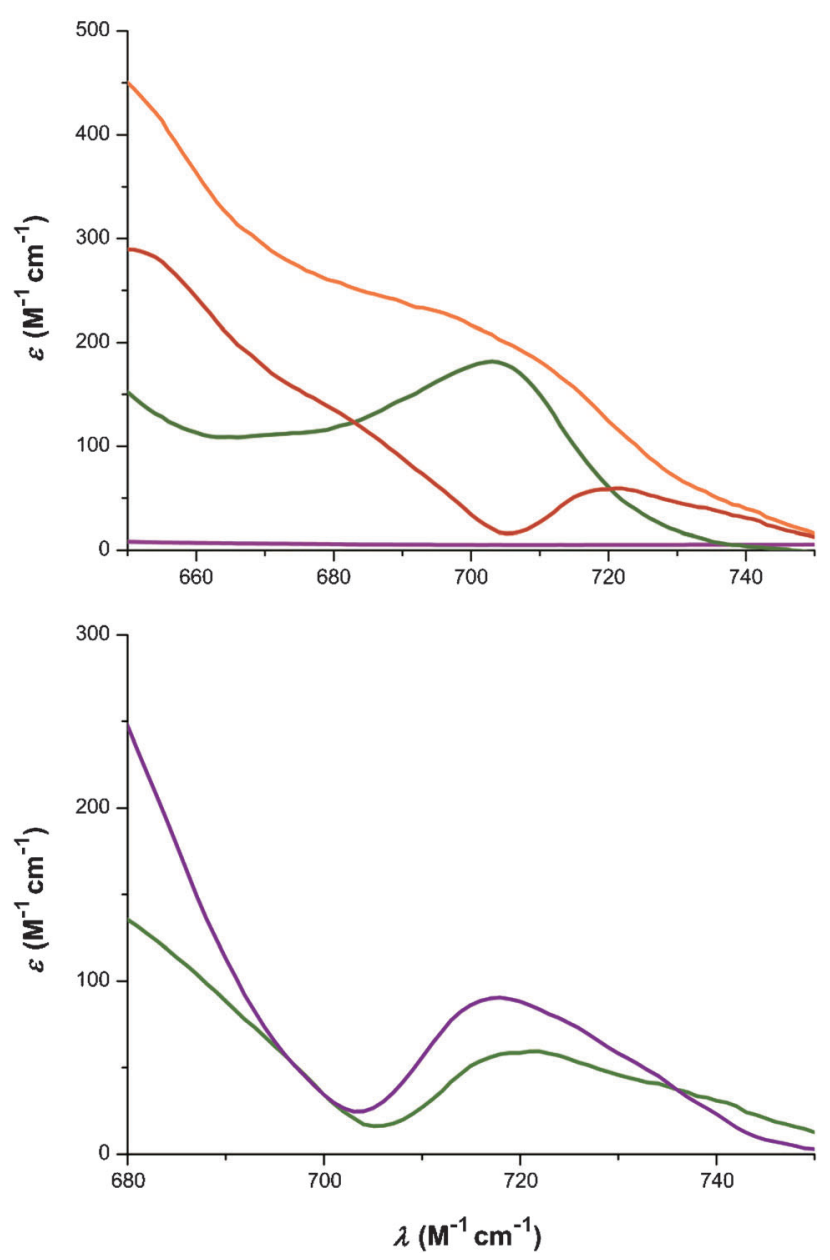

Figure 3. Top: Charge-transfer absorption (red line) of a solution of $\mathbf{2}$ in toluene. The concentration of all compounds was $2.6 \times 10^{-5} \mathrm{M}$. Orange line: 2; purple line: $\mathrm{C}_{60}$-ref; green line: ZnTPP. Bottom: Charge-transfer absorption of a solution of $\mathbf{1}$ (purple line) and $\mathbf{2}$ (green line) in toluene.

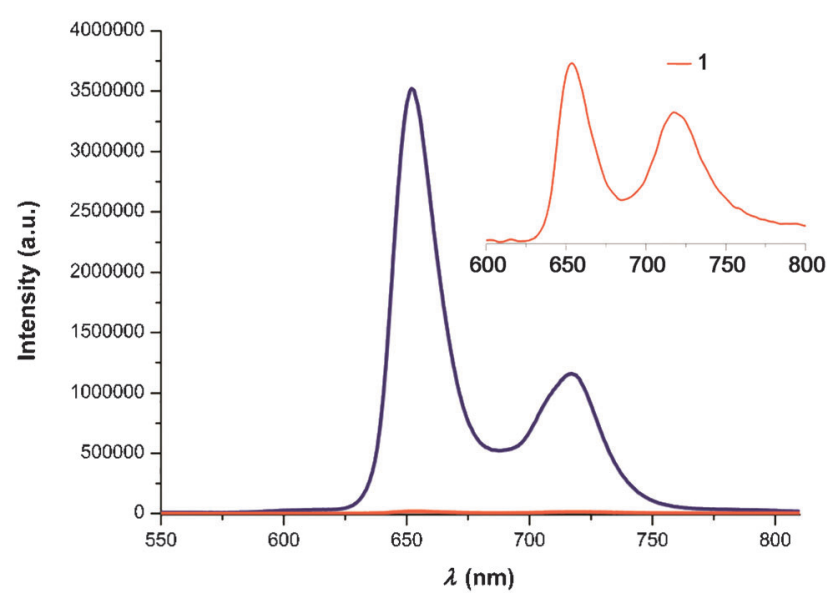

Figure 4. Room-temperature fluorescence spectra of $\mathrm{H}_{2} \mathrm{TPP}$ in toluene (blue line) and $\mathbf{1}$ in toluene (red line) upon excitation at $415 \mathrm{~nm}$. The insert shows emission bands of $\mathbf{1}$.

were found at 587 and $635 \mathrm{~nm}$. These maxima are red shifted to 602 and $653 \mathrm{~nm}$ in THF and to 607 and $658 \mathrm{~nm}$ in 
Table 3. Fluorescence properties (emission maxima, $\lambda_{\mathrm{em}}[\mathrm{nm}]$, and quantum yields, $\Phi)$ of $\mathbf{1}$ and $\mathbf{2}$ in different solvents at room temperature.

\begin{tabular}{lcccc}
\hline Solvent & \multicolumn{2}{c}{$\mathbf{1}^{[\mathrm{a}]}$} & \multicolumn{2}{c}{$\mathbf{2}^{[\mathrm{b}]}$} \\
& $\lambda_{\mathrm{em}}[\mathrm{nm}]$ & $\boldsymbol{\Phi}$ & $\lambda_{\mathrm{em}}[\mathrm{nm}]$ & $\Phi$ \\
\hline toluene & 653,718 & 0.0019 & 596,644 & 0.0012 \\
THF & 653,718 & 0.0015 & 602,653 & 0.0014 \\
PhCN & 653,718 & 0.00096 & 607,658 & 0.0035 \\
\hline
\end{tabular}

[a] Excitation wavelength: $415 \mathrm{~nm}$. [b] Excitation wavelength: $419 \mathrm{~nm}$

$\mathrm{PhCN}$. For 2, the underlying trend is, however, attributed to the coordination of the solvent. Compound $\mathbf{2}$ features a much lower fluorescence quantum yield $\left(\Phi=1.2 \times 10^{-3}\right)$ relative to 1 (vide supra) and ZnTPP $(\Phi=0.04$ ), but no substantial differences in the fluorescence quantum yield were observed in the more polar solvents (Table 3 ).

Compounds 1 and 2 also exhibit broad emission bands in the near-infrared with maxima between 850 and $1000 \mathrm{~nm}$ (Figure 5). In line with other porphyrin-fullerene conjuga-



Figure 5. Room-temperature near-infrared emission spectra of $\mathbf{2}$ in toluene (red line), and $\mathrm{PhCN}$ (purple line) upon excitation at $419 \mathrm{~nm}$.

tes, ${ }^{[3 \mathrm{~d}, 9]}$ this band is assigned to charge-transfer emission. To confirm this assignment, the emission spectra were recorded in solvents of increasing polarity (i.e., toluene, THF, and $\mathrm{PhCN}$ ). Within this series, the emission intensity decreases as the solvent polarity increases (Figure 5). Please note that in benzonitrile the near-infrared emission is hardly visible. The solvent effect also results in a redshift from $947 \mathrm{~nm}$ in toluene to $965 \mathrm{~nm}$ in $\mathrm{PhCN}$. A similar trend was observed for $\mathbf{1}$, but with lower quantum yields. Here, the maxima shift from $923 \mathrm{~nm}$ in toluene to $934 \mathrm{~nm}$ in THF. In summary, a low-lying charge-transfer state that is subject to a radiative deactivation to the ground state is formed in $\mathbf{1}$ and $\mathbf{2}$. Its energy decreases strongly as solvent polarity increases.

Transient absorption spectroscopy: Transient absorption measurements were used to test the lifetimes of the excited species and the nature of the deactivation processes following photoexcitation. Allthe compounds were excited at $420 \mathrm{~nm}$ in toluene, THF, and PhCN. The differential absorp- tion spectra of ZnTPP and $\mathrm{H}_{2}$ TPP upon $420 \mathrm{~nm}$ excitation in toluene are shown in the Supporting Information (Figures S2 and S3). These help to interpret the results for $\mathbf{1}$ and 2. A nearly instantaneous formation of the singlet excited state of porphyrin is observed for ZnTPP and $\mathrm{H}_{2}$ TPP. In the case of $\mathrm{ZnTPP}$, the singlet excited state is formed in toluene in $0.6 \mathrm{ps}$ and features minima at 551 and $592 \mathrm{~nm}$ and a maximum at $621 \mathrm{~nm}$. The minima correspond with the maxima seen in the ZnTPP ground-state absorption. As time increases, we note that the singlet excited state features fade out and that new absorption bands develop at 480 and $820 \mathrm{~nm}$. The latter relate to the triplet excited state and, as such, imply an intersystem crossing that transforms the ZnTPP singlet excited state into the corresponding triplet excited state. ${ }^{[12]}$ For $\mathrm{H}_{2}$ TPP, the singlet excited state is formed in $0.8 \mathrm{ps}$ in toluene. Bleaching of the ground state is visible at $521,555,598$, and $652 \mathrm{~nm}$.

When investigating $\mathbf{1}$ and $\mathbf{2}$ in a solution of toluene, we focused our attention on the generation of the singlet excited state. In fact, the same singlet excited states found for $\mathrm{H}_{2}$ TPP and ZnTPP were seen to develop upon photoexcitation of $\mathbf{1}$ and $\mathbf{2}$, despite the presence of the electron-accepting fullerene. This is taken as evidence for the successful photoexcitation of the chromophores in the electron donoracceptor conjugates in all three solvents. However, at longer delay times, compounds $\mathbf{1}$ and $\mathbf{2}$ reveal a different behavior than that seen for the references.

The differential absorption spectra of $\mathbf{2}$ in toluene are summarized in Figure 6. The corresponding differential absorption spectra in $\mathrm{THF}$ and $\mathrm{PhCN}$ are given in Figures $\mathrm{S} 7$ and S8 of the Supporting Information, respectively. In all of the cases, the formation of the singlet excited state in form of the $435 \mathrm{~nm}$ maximum is observed within $0.5 \mathrm{ps}$. At the end of the singlet decay, new transient features emerged with maxima in the visible and near-infrared regions, for example, for 2 . In the visible, a broad band with a maximum at $621 \mathrm{~nm}$ corresponds to the one-electron oxidized ZnTPP $\left(\mathrm{ZnTPP}^{\cdot+}\right)$, whereas the near-infrared maximum at $1021 \mathrm{~nm}$ agrees well with the fingerprint of the one-electron reduced $\mathrm{C}_{60}\left(\mathrm{C}_{60}{ }^{\cdot-}\right) \cdot{ }^{[2 \mathrm{f}, \mathrm{h}, 5]}$ In addition, no intersystem crossing between the singlet excited state and the triplet excited state of ZnTPP was observable. This led us to conclude that an intramolecular electron transfer converts the initial excited state into a charge-separated state.

In toluene, the $\mathrm{ZnTPP}^{+}+$lifetime is $2.2 \mathrm{~ns}$, and the $\mathrm{C}_{60}{ }^{-}$ lifetime is $1.7 \mathrm{~ns}$. Upon increasing the solvent polarity, the band at $621 \mathrm{~nm}$ shifts to 636 and $628 \mathrm{~nm}$ with lifetimes of 90 and $692 \mathrm{ps}$ in $\mathrm{PhCN}$ and THF, respectively. In general, the features of 1 (Figures S4-S6 of the Supporting Information) are similar to those discussed above for $\mathbf{2}$. The only noticeable differences are the formation and the decay of the charge-separated states. In particular, they are formed faster in $\mathbf{2}$ than in $\mathbf{1}$ with rise times of $0.8 \mathrm{ps}$ in toluene, $0.77 \mathrm{ps}$ in $\mathrm{THF}$, and $0.78 \mathrm{ps}$ in $\mathrm{PhCN}$ versus $1.1 \mathrm{ps}$ in toluene, $1.09 \mathrm{ps}$ in $\mathrm{THF}$, and $1.1 \mathrm{ps}$ in PhCN. Moreover, the charge-separatedstate lifetimes for $\mathbf{1}$ tend to be longer than in $\mathbf{2}$ with values of $3.3,1.4$, and $0.51 \mathrm{~ns}$ in toluene, $\mathrm{THF}$, and $\mathrm{PhCN}$, respec- 



Figure 6. Top: Differential absorption spectra (visible and near-infrared) obtained upon femtosecond flash photolysis $(420 \mathrm{~nm})$ of $\mathbf{2}\left(\approx 1 \times 10^{-6} \mathrm{M}\right)$ in toluene with time delays of 4.99 and $5000 \mathrm{ps}$ at room temperature. Purple circle: 4.99; yellow circle: 5000. Bottom: Time absorption profile of the spectra shown above at 454 (purple circle), 618 (yellow circle), and $1021 \mathrm{~nm}$ (brown circle), reflecting the intramolecular electron-transfer dynamics.

tively. All of these data are comparable to those reported in the literature ${ }^{[3 \mathrm{~d}, 9]}$ for porphyrin-fullerene conjugates with similar geometries.

Quantum chemical investigations: We also performed computational studies with $\mathbf{1}$ and $\mathbf{2}$, and the related $\mathrm{C}_{60}$-ref, $\mathrm{H}_{2}$ TPP, and ZnTPP to gain further insight into the experimentally observed phenomena. All structures were optimized at the $\omega \mathrm{B} 97 \mathrm{XD}^{[13]} / 6-31 \mathrm{G}(\mathrm{d})^{[14]}$ level. Molecular orbital analyses were performed at the same level of theory. ${ }^{[15]}$ All calculations were performed using the Gaussian 09 ${ }^{[16]}$ program package.

As expected, the $\mathrm{C}_{60}$ moieties in $\mathbf{1}$ and $\mathbf{2}$ behave as electron acceptors. In fact, the LUMO energy of $\mathrm{C}_{60}$-ref matches closely those of both porphyrin-fullerene conjugates (Figure 7 and Figure 8). Similarly, the HOMOs in $\mathbf{1}$ and $\mathbf{2}$ are located on the porphyrins with $\mathrm{HOMO}$ energies that match those of $\mathrm{H}_{2}$ TPP and ZnTPP, respectively. These findings are in excellent agreement with earlier calculations ${ }^{[17]}$ of similar porphyrin- $\beta$-oligo(ethynylenephenylene)-fuller-

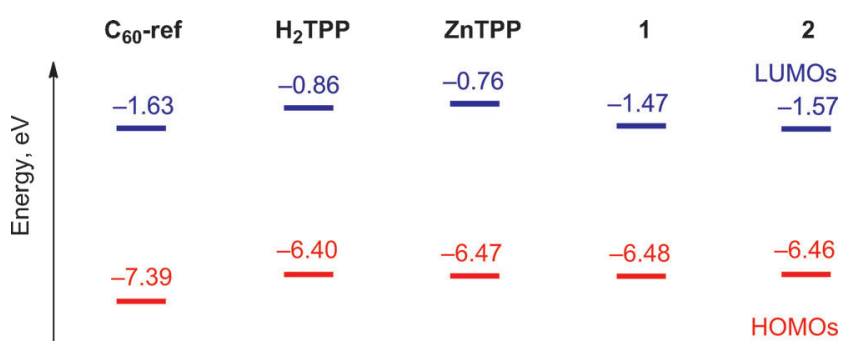

Figure 7. HOMO/LUMO energies of 1, 2, $\mathrm{C}_{60}$-ref, $\mathrm{H}_{2} \mathrm{TPP}$, and $\mathrm{ZnTPP}$ at the $\omega \mathrm{B} 97 \mathrm{XD} / 6-31 \mathrm{G}(\mathrm{d})$ level $[\mathrm{eV}]$.
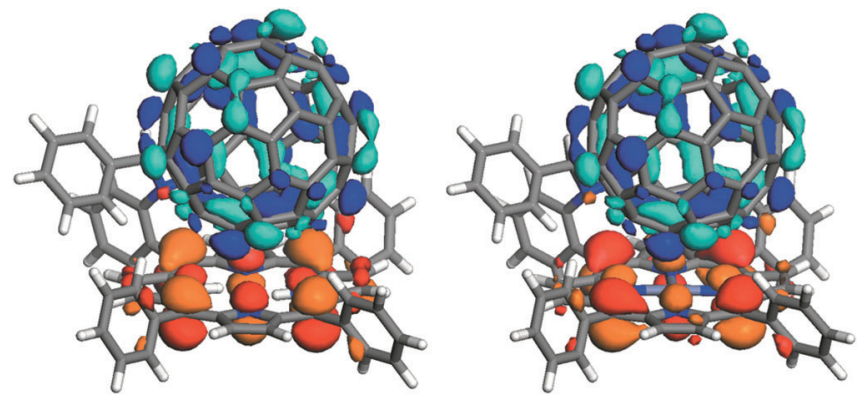

Figure 8. HOMOs (red-orange) and LUMOs (blue-cyan) of 1 (left) and 2 (right) at $\omega \mathrm{B} 97 \mathrm{XD} / 6-31 \mathrm{G}(\mathrm{d})$ displaying their electron donor-acceptor character.

ene conjugates that bear oligo(ethynylenephenylene) (oligoPPE) bridges.

The local electron affinity $\left.\mathrm{EA}_{\mathrm{L}}\right)^{[18]}$ mapped onto the standard isodensity surface of $\mathbf{1}$ and $\mathbf{2}$ was computed with Parasurf $11^{[19]}$ and visualized using Molcad $\mathrm{II}^{[20]}$ from PM6 ${ }^{[21]}$ calculations with semiempirical MO program VAMP 11.0 $0^{[22]}$ at the $\omega \mathrm{B} 97 \mathrm{XD} / 6-31 \mathrm{G}(\mathrm{d})$ geometries. This analysis (Figure 9) confirms that the strongest electron acceptors are the fullerenes and the strongest donors are the porphyrins. Note that the $\mathrm{EA}_{\mathrm{L}}$ is higher at the center of zinc porphyrin because of the substantial positive charge of zinc. This renders the porphyrin in $\mathbf{2}$ a stronger electrondonor than in $\mathbf{1}$, which helps to explain the faster charge-separation dynamics observed for $\mathbf{2}$ than with $\mathbf{1}$.

As in all theoretical studies, it is important to calibrate the performance of the level of theory used for the problem. We have therefore calculated the wavelengths and intensities of the absorption bands by using the PM6 UNO-CIS (unrestricted natural orbital, configuration interaction singles) method with AM1 density matrices for the initial guess as implemented in VAMP 11.0. This technique has been shown ${ }^{[23]}$ to give good agreement with experiments for optical bandgaps for a series of organic compounds such as polyynes and polycyclic aromatics. The absorption spectra were also calculated with the conventional PM6 CIS method by using the same number of orbitals in the active space as predicted by the PM6 UNO-CIS method, that is, 74 for $\mathbf{1}$ and 66 for 2 . In addition, calculations were performed with statistical averaging of orbital potentials ${ }^{[24]}$ (SAOP) using TZP basis sets as implemented in the Amsterdam density functional (ADF) package. ${ }^{[25]}$ The number of orbitals needed to 


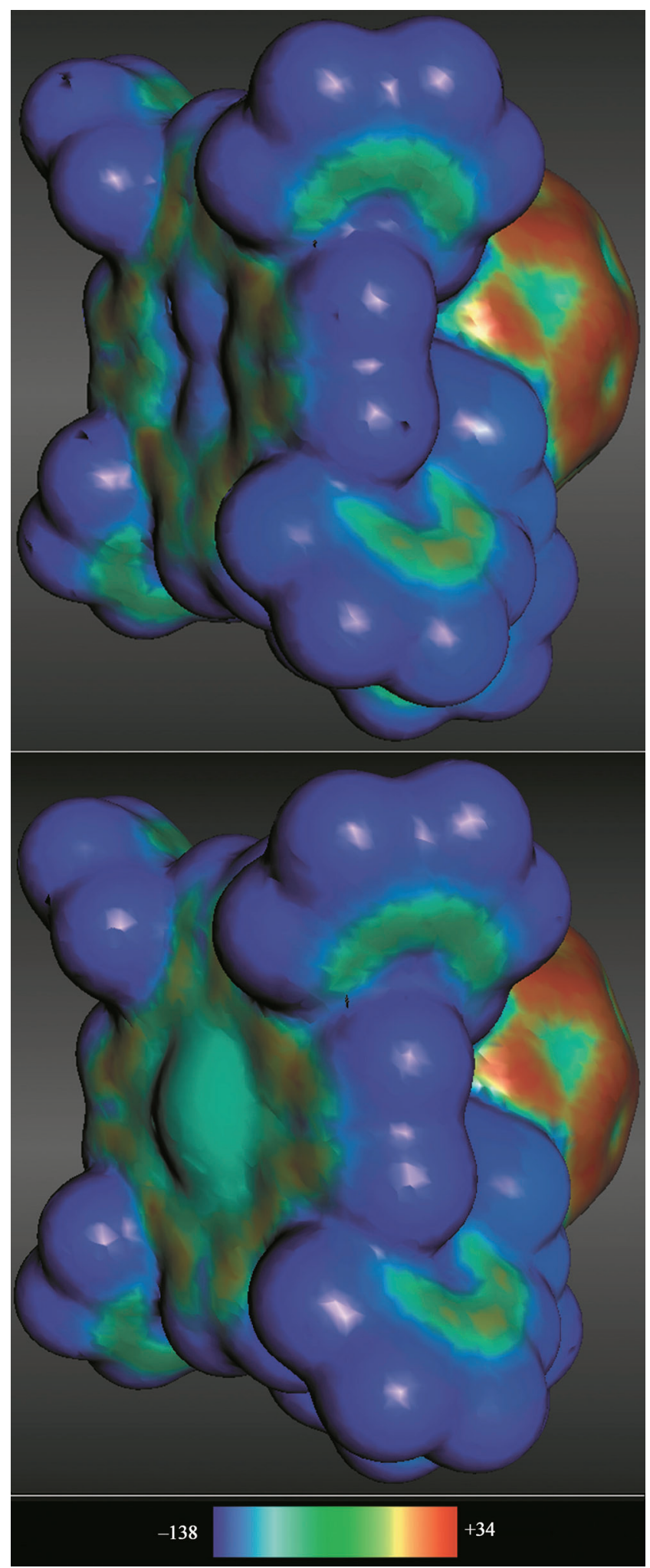

Figure 9. Local electron affinity $\left(\mathrm{EA}_{\mathrm{L}}\right)$ isosurfaces of $\mathbf{1}$ (top) and $\mathbf{2}$ (bottom) at PM6 in toluene on $\omega \mathrm{B} 97 \mathrm{XD} / 6-31 \mathrm{G}(\mathrm{d})$ geometries. The color scale $\left[\mathrm{kcal} \mathrm{mol}^{-1}\right]$ is shown below the figure. The local electron affinity is defined in the literature. ${ }^{[18 b]}$ simulate the spectra in the major part of the experiments for SAOP/TZP is 180 . Spectra calculated in the gas phase and in the different solvents at the PM6 UNO-CIS, PM6 CIS, and SAOP/TZP levels on the $\omega$ B97XD/6-31G(d) geometries are shown in Figures S9 and S10 of the Supporting Information.

The PM6 UNO-CIS method predicts that the lowestenergy $\mathrm{Q}$ band of $\mathbf{1}$ is around $622 \mathrm{~nm}$ in toluene, which is in good agreement with corresponding experimental value of approximately $654 \mathrm{~nm}$ compared to $653 \mathrm{~nm}$ predicted by SAOP/TZP and to $620 \mathrm{~nm}$ at PM6 CIS. The position of the longest-wavelength $\mathrm{Q}$ band for $\mathbf{2}$ in toluene is best predicted by the PM6 UNO-CIS method. The corresponding calculated values are 526, 652, and $656 \mathrm{~nm}$ at PM6 CIS, PM6 UNOCIS, and SAOP/TZP, respectively, compared with the experimental value of $592 \mathrm{~nm}$.

Nevertheless, the energies of the Soret band in toluene are too high at PM6 UNO-CIS. For 1 they are 401, 358, and $439 \mathrm{~nm}$, whereas for 2 they evolve at 385,334 , and $436 \mathrm{~nm}$ at PM6 CIS, PM6 UNO-CIS, and SAOP/TZP, respectively, relative to the experimental values of 428 for $\mathbf{1}$ and $431 \mathrm{~nm}$ for 2.

The influence of the solvent polarity on the electronic transitions in $\mathbf{1}$ and $\mathbf{2}$ (Figures S9 and S10 of the Supporting Information) was also studied computationally. The solvent effects were considered using the conductor-like screening model (COSMO $)^{[26]}$ for SAOP and the self-consistent reaction field (SCRF) theory with the polarizable continuum model (PCM) $)^{[27]}$ for semiempirical UNO-CIS and CIS calculations. Nevertheless, no significant solvent dependence was observed in the simulated UV/Vis absorption spectra.

HOMO-LUMO transitions are involved in the formation of the first singlet excited states of $\mathbf{1}$ and $\mathbf{2}$ at the SAOP/ TZP level (Figure S11 of the Supporting Information). These transitions correspond to $\pi$-porphyrin $\rightarrow \pi$-C60 transitions and, thus, to charge-transfer transitions.

However, the energies of the lowest charge-transfer transitions above the ground states are underestimated at SAOP/TZP: the calculated values are 1.18 and $1.10 \mathrm{eV}$ for $\mathbf{1}$ and $\mathbf{2}$ in toluene, respectively, compared with experimental values of 1.73 and $1.72 \mathrm{eV}$, respectively. The oscillator strengths of these transitions are $10^{3}$ times lower than those of the Soret band transitions, compared with an experimental factor of approximately $10^{3}$ (Table S1 of the Supporting Information).

Both PM6 CIS and UNO-CIS calculations also suggest that HOMO-LUMO transitions are involved in the formation of the lowest-lying singlet charge-transfer state in toluene. The changes in the dipole moment calculated by PM6 UNO-CIS relative to the ground state are 11.5 and $14.8 \mathrm{D}$ in $\mathbf{1}$ and 2, respectively, and 16.7 and 14.4 D at PM6 CIS. The Coulson charge on $\mathrm{C}_{60}$ in $\mathbf{1}$ and $\mathbf{2}$ (between -0.1 and $-0.06 e$ in the ground state) increases to -1.0 to $-0.78 e$ in the charge-transfer state at PM6 CIS and UNO-CIS (Table S2 of the Supporting Information). Visualization of the electrostatic potentials also confirms that charge transfer occurs in these excitations (Figure 10 and Figure S12 of the Support- 


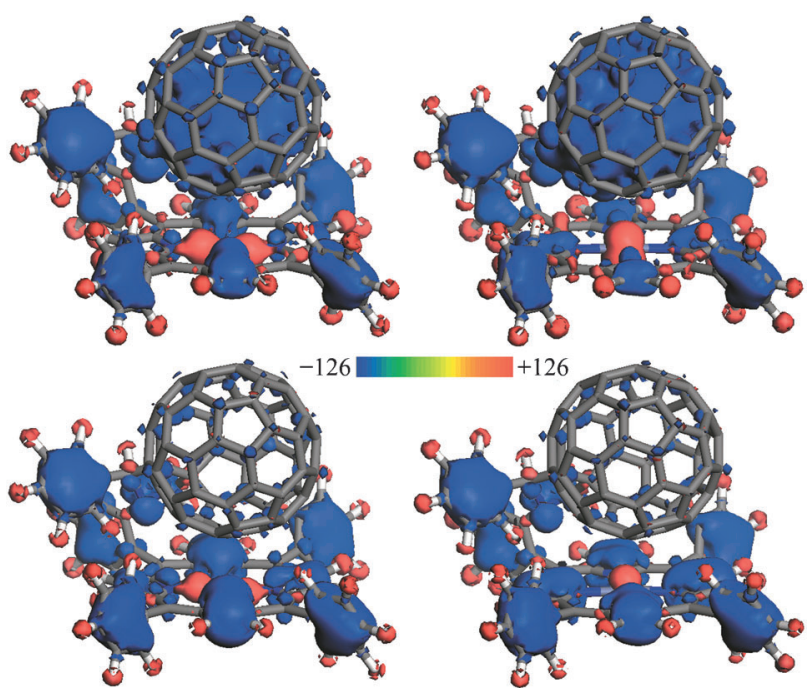

Figure 10. Isopotential surfaces for the molecular electrostatic potentials of ground states (bottom) and CT states (top) of $\mathbf{1}$ (left) and $\mathbf{2}$ (right) from PM6 UNO-CIS calculations. The color scale $\left[\mathrm{kcal} \mathrm{mol}^{-1}\right]$ is shown in the middle of the figure.

ing Information). Molecular orbitals and electrostatic potentials were visualized with Materials Studio 6.0. ${ }^{[28]}$

PM6 UNO-CIS gives the lowest CT state of $\mathbf{1}$ at $2.36 \mathrm{eV}$ and of 2 at $2.41 \mathrm{eV}$ above the ground states. Likewise, PM6 CIS leads to values of 2.35 and $2.14 \mathrm{eV}$ for $\mathbf{1}$ and $\mathbf{2}$, respectively. These values, which were calculated in toluene, are in fair agreement ( 0.4 to $0.6 \mathrm{eV}$ higher in energy) with the experimental absorption charge-transfer bands of $\mathbf{1}$ at 1.73 and 2 at $1.72 \mathrm{eV}$ in the same solvent. These charge-transfer states are stabilized by $0.10-0.14 \mathrm{eV}$ in toluene relative to the gas phase (Table S2 of the Supporting Information) because of their high dipole moments. Their oscillator strengths are lower by more than a factor of $10^{3}$ than those of the Soret band transitions (Table S3 of the Supporting Information), which agree well with the experimental intensities of these transitions.

The calculations confirm the known trends of DFT-based and semiempirical CI techniques to under- and overestimate the energies of charge-transfer transitions, respectively. The errors are close to equal but in opposite directions. A pragmatic approach would be simply to average the SAOP/TZP and PM6 UNO-CIS transition energies to obtain a closer estimate relative to the experimental results.

As expected, the relative positions of the porphyrins and $\mathrm{C}_{60}$ moieties have a large influence on the electron-transfer process. Donor and acceptor are very closely located in $\mathbf{1}$ and $\mathbf{2}$, so it is important to take noncovalent interactions between the porphyrins and $\mathrm{C}_{60}$ moieties into account. We have therefore used the $\omega \mathrm{B} 97 \mathrm{XD}$ functional, which includes dispersion corrections. Indeed, the optimized geometries depend strongly on the level of theory used for the optimization (Figure S15 of the Supporting Information). The calculated distance between donor and acceptor is approximately $3 \AA$ at $\omega \mathrm{B} 97 \mathrm{XD} / 6-31 \mathrm{G}(\mathrm{d})$, which is in excellent agreement with that obtained using the $\mathrm{MM}+$ force field $^{[10]}$ and with experimental distances between nonbonded porphyrins and $\mathrm{C}_{60}$ moieties in cocrystallates. ${ }^{[6]}$ The B3PW91 ${ }^{[15]}$ functional, which does not include a dispersion correction, gives an optimized distance between donor and acceptor of more than $4 \AA$, whereas it is more than $8 \AA$ at PM6.

\section{Conclusion}

The two electron donor-acceptor conjugates ( $\mathbf{1}$ and $\mathbf{2}$ )-one of which features a porphyrin-free base, and one of which features a zinc porphyrin-described in this work differ fundamentally from those reported to date because of the direct linkers between the carbon of the phenyl ring and the pyrrolidine nitrogen, which results in a completely frozen geometry. This geometrical constraint leads to fast photoinduced electron transfer as evidenced by a decay in just a few picoseconds of the porphyrin singlet excited state. The resulting charge-separated states are long-lived, with lifetimes of 506 ps for $\mathbf{1}$ and 90 ps for $\mathbf{2}$. DFT and semiempirical UNO-CIS calculations show that the HOMOs and LUMOs are localized on the porphyrin donor and the $\mathrm{C}_{60}$ acceptor, respectively, and HOMO-LUMO excitations therefore lead to the charge-transfer states. The energies of frontier orbitals of $\mathbf{1}$ and $\mathbf{2}$ correspond to those of the porphyrin and $\mathrm{C}_{60}$ references. The presence of zinc in the center of the porphyrin changes its local electronic properties and leads to faster electron-transfer dynamics. Calculated electronic-transition energies and intensities agree reasonably well with the experimental results, which reveals that DFT and semiempirical UNO-CI methods under- and overestimate the transition energies by the same amount, namely, approximately $0.6 \mathrm{eV}$ in toluene.

Compounds $\mathbf{1}$ and $\mathbf{2}$ form an ideal basis for future optimized donor-acceptor conjugates for charge separation, in which other photo- or electroactive moieties can be incorporated.

\section{Experimental Section}

General methods: ${ }^{1} \mathrm{H}$ NMR spectra were recorded in $\mathrm{CDCl}_{3}$ solutions using a Brucker AM-300 instrument with tetramethylsilane (TMS) as internal standard. Ultraviolet-visible (UV/Vis) spectra were recorded using a Varian Cary 5000 Scan spectrophotometer and a Perkin-Elmer Lambda $2 \mathrm{UV} /$ Vis double-beam spectrophotometer with a slit width of $2 \mathrm{~nm}$ and scan rate of $480 \mathrm{nmmin}^{-1}$. Steady-state fluorescence studies were carried out using a Horiba Jobin Yvon FluoroMax-3 spectrometer with a slit width of $2 \mathrm{~nm}$ for excitation and emission and an integration time of $0.5 \mathrm{~s}$. All spectra were corrected for the instrument response. The emission lifetimes for time-resolved fluorescence measurements were determined by means of time-correlated single-photon counting (TCSPC) using a Horiba Jobin Yvon FluoroLog3 emission spectrometer. For excitation, a laser diode (NanoLED-405L, $403 \mathrm{~nm}$, pulse width of $\leq 200 \mathrm{ps}$, maximum repetition rate $100 \mathrm{kHz}$ ) was used. The femtosecond transient absorption studies were performed with 387 and $420 \mathrm{~nm}$ laser pulses (1 kHz $150 \mathrm{fs}$ pulse width) from an amplified Ti:sapphire laser system (model CPA 2101, Clark-MXR Inc.). Electrochemical data were obtained by cyclic voltammetry using a conventional three-electrode cell in combination with an AUTOLAB eco chemie potentiostat. Platinum and silver 
wires were used as counter- and pseudo-reference electrodes, respectively. A glassy carbon electrode (GCE) was used as the working electrode. The measurements were carried out in 1,2-dichlorbenzene (o-DCB) with $0.1 \mathrm{~m}$ tetra- $n$-butylammonium hexafluorophosphate $\left(\mathrm{TBAPF}_{6}\right)$ as supporting electrolyte.

Chemicals: Silica gel 60 (60-240 Merck) was used for column chromatography. $o$-DCB for electrochemistry and tetra- $n$-butylammonium hexafluorophosphate $\left(\mathrm{TBAPF}_{6}\right)$ were purchased from the Aldrich Chemical Co. $\mathrm{C}_{60}$ was purchased from Term-USA. All other reagents and solvents were supplied from Fluka Chem. Co., Aldrich Chem. Co., or Carlo Erba and used as received.

Synthesis: The preparation of $\mathbf{1}$ has been described previously. ${ }^{[10]}$ For 2, a saturated solution of $\mathrm{Zn}(\mathrm{OAc})_{2}$ in methanol was added to a solution of $\mathbf{1}$ in chloroform. The mixture was left to react at room temperature under nitrogen for $2 \mathrm{~h}$. The solvent was evaporated and the product was purified using a plug of silica gel and eluting with chloroform. Yield: $97 \%$. ${ }^{1} \mathrm{H}$ NMR $\left(300 \mathrm{Mz}, \mathrm{CDCl}_{3}\right.$ ): $\delta=9.3-8.7$ (series of broadened doublets and multiplets, $8 \mathrm{H}$; $\beta$-pyrrole protons) $8.27-7.84$ (brm, $5 \mathrm{H}$; phenyl protons), 7.79 (brs, $10 \mathrm{H}$; phenyl protons) 7.5 (m, $5 \mathrm{H}$; phenyl of pyrrolidine), 5.45 (s, $1 \mathrm{H} ; \mathrm{CH}$ of pyrrolidine ring), $3.77(\mathrm{~d}, 1 \mathrm{H}$; methylene group of pyrrolidine), $3.33 \mathrm{ppm}(\mathrm{d}, 1 \mathrm{H}$; methylene group of pyrrolidine); UV/Vis (toluene): $\lambda_{\max }(\varepsilon)=312 \quad(70258), 430 \quad(337453), 553 \quad(21048), 592 \mathrm{~nm}$ $\left(6410 \mathrm{M}^{-1} \mathrm{~cm}^{-1}\right)$; MS (FAB): $\mathrm{m} / z$ : calcd: $1515\left[\mathrm{M}^{+}\right]$; found: $1515.93\left[\mathrm{M}^{+}\right]$.

\section{Acknowledgements}

P.O.D. gratefully acknowledges Universität Bayern e.V. for the graduate stipend, which was provided on the basis of the Bavarian Elite Aid Act, and the Graduate School of Molecular Science for support. This work was supported by a grant of computer time on HRLB II at the Leibniz Rechenzentrum Munich. The authors thank Tatyana E. Shubina for a discussion of SAOP calculations. P.T. acknowledges the Italian PRIN for financial support.

[1] a) H. Imahori, Y. Sakata, Adv. Mater. 1997, 9, 537-546; b) H. Imahori, Y. Sakata, Eur. J. Org. Chem. 1999, 2445-2457; c) D. M. Guldi, Chem. Commun. 2000, 321-327; d) D. M. Guldi, M. Prato, Acc. Chem. Res. 2000, 33, 695-703.

[2] a) S. Fukuzumi, H. Imahori in Electron Transfer in Chemistry, Vol. 2 (Ed.: V. Balzani), Wiley-VCH, Weinheim, 2001, pp. 927-975; b) S. Fukuzumi, H. Imahori, H. Yamada, M. E. El-Khouly, M. Fujitsuka, O. Ito, D. M. Guldi, J. Am. Chem. Soc. 2001, 123, 2571-2575; c) D. Gust, T. A. Moore in The Porphyrin Handbook, Vol. 8 (Ed.: K. M. S. K. M. Kadish, R. Guilard), Academic Press, San Diego, 2000, pp. 153-190; d) D. Gust, T. A. Moore, A. L. Moore, Acc. Chem. Res. 2001, 34, 40-48; e) D. Gust, T. A. Moore, A. L. Moore in Electron Transfer in Chemistry, Vol. 2 (Ed.: V. Balzani), WileyVCH, Weinheim, 2001, pp. 272-336; f) H. Imahori, D. M. Guldi, K. Tamaki, Y. Yoshida, C. Luo, Y. Sakata, S. Fukuzumi, J. Am. Chem. Soc. 2001, 123, 6617-6628; g) H. Imahori, Y. Mori, Y. Matano, J. Photochem. Photobiol. C 2003, 4, 51-83; h) H. Imahori, K. Tamaki, D. M. Guldi, C. Luo, M. Fujitsuka, O. Ito, Y. Sakata, S. Fukuzumi, J. Am. Chem. Soc. 2001, 123, 2607-2617; i) H. Imahori, K. Yamada, M. Hasegawa, S. Taniguchi, T. Okada, Y. Sakata, Angew. Chem. 1997, 109, 2740-2742; Angew. Chem. Int. Ed. Engl. 1997, 36, 26262629.

[3] a) J.-P. Bourgeois, F. Diederich, L. Echegoyen, J.-F. Nierengarten, Helv. Chim. Acta 1998, 81, 1835-1844; b) N. Armaroli, G. Marconi, L. Echegoyen, J.-P. Bourgeois, F. Diederich, Chem. Eur. J. 2000, 6, 1629-1645; c) D. M. Guldi, A. Hirsch, M. Scheloske, E. Dietel, A. Troisi, F. Zerbetto, M. Prato, Chem. Eur. J. 2003, 9, 4968-4979; d) N. Armaroli, G. Accorsi, F. Song, A. Palkar, L. Echegoyen, D. Bonifazi, F. Diederich, ChemPhysChem 2005, 6, 732-743; e) D. Bonifazi, G. Accorsi, N. Armaroli, F. Song, A. Palkar, L. Echegoyen,
M. Scholl, P. Seiler, B. Jaun, F. Diederich, Helv. Chim. Acta 2005, 88 , 1839-1884.

[4] a) D. I. Schuster, P. Cheng, P. D. Jarowski, D. M. Guldi, C. Luo, L. Echegoyen, S. Pyo, A. R. Holzwarth, S. E. Braslavsky, R. M. Williams, G. Klihm, J. Am. Chem. Soc. 2004, 126, 7257-7270; b) T. Galili, A. Regev, H. Levanon, D. I. Schuster, D. M. Guldi, J. Phys. Chem. A 2004, 108, 10632-10639.

[5] F. D'Souza, E. Maligaspe, P. A. Karr, A. L. Schumacher, M. E. Ojaimi, C. P. Gros, J.-M. Barbe, K. Ohkubo, S. Fukuzumi, Chem Eur. J. 2008, 14, 674-681.

[6] a) P. D. W. Boyd, M. C. Hodgson, C. E. F. Rickard, A. G. Oliver, L. Chaker, P. J. Brothers, R. D. Bolskar, F. S. Tham, C. A. Reed, J. Am Chem. Soc. 1999, 121, 10487-10495; b) M. M. Olmstead, D. A Costa, K. Maitra, B. C. Noll, S. L. Phillips, P. M. V. Calcar, A. L. Balch, J. Am. Chem. Soc. 1999, 121, 7090-7097; c) D. I. Schuster P. D. Jarowski, A. N. Kirschner, S. R. Wilson, J. Mater. Chem. 2002, 12, 2041-2047.

[7] N. Acar, J. Kurzawa, N. Fritz, A. Stockmann, C. Roman, S. Schneider, T. Clark, J. Phys. Chem. A 2003, 107, 9530-9541.

[8] D. Kuciauskas, S. Lin, G. R. Seely, A. L. Moore, T. A. Moore, D Gust, T. Drovetskaya, C. A. Reed, P. D. W. Boyd, J. Phys. Chem.J. Phys. Chem. A 1996, 100, 15926-15932.

[9] N. V. Tkachenko, H. Lemmetyinen, J. Sonoda, K. Ohkubo, T. Sato, H. Imahori, S. Fukuzumi, J. Phys. Chem. A 2003, 107, 8834-8844.

[10] A. Lembo, P. Tagliatesta, D. Cicero, A. Leoni, A. Salvatori, Org. Biomol. Chem. 2009, 7, 1093-1096.

[11] a) Y.-B. Wang, Z. Lin, J. Am. Chem. Soc. 2003, 125, 6072-6073; b) P. D. W. Boyd, C. A. Reed, Acc. Chem. Res. 2005, 38, 235-242.

[12] T. Nojiri, A. Watanabe, O. Ito, J. Phys. Chem. A 1998, 102, 52155219.

[13] J.-D. Chai, M. Head-Gordon, Phys. Chem. Chem. Phys. 2008, 10, $6615-6620$.

[14] a) J. S. Binkley, J. A. Pople, W. J. Hehre, J. Am. Chem. Soc. 1980, 102, 939-947; b) R. C. Binning Jr., L. A. Curtiss, J. Comput. Chem. 1990, 11, 1206-1216; c) J.-P. Blaudeau, M. P. McGrath, L. A. Curtiss, L. Radom, J. Chem. Phys. 1997, 107, 5016-5021; d) R. Ditchfield, W. J. Hehre, J. A. Pople, J. Chem. Phys. 1971, 54-55, 724; e) M. M. Francl, W. J. Pietro, W. J. Hehre, J. S. Binkley, D. J. DeFrees, J. A Pople, M. S. Gordon, J. Chem. Phys. 1982, 77, 3654-3665; f) M. S. Gordon, Chem. Phys. Lett. 1980, 76, 163-168; g) M. S. Gordon, J. S Binkley, J. A. Pople, W. J. Pietro, W. J. Hehre, J. Am. Chem. Soc 1982, 104, 2797-2803; h) P. C. Hariharan, J. A. Pople, Theor. Chem. Acc. 1973, 28, 213-222; i) P. C. Hariharan, J. A. Pople, Mol. Phys. 1974, 27, 209-214; j) W. J. Hehre, R. Ditchfield, J. A. Pople, J. Chem. Phys. 1972, 56, 2257; k) V. A. Rassolov, J. A. Pople, M. A Ratner, T. L. Windus, J. Chem. Phys. 1998, 109, 1223-1229; 1) V. A Rassolov, M. A. Ratner, J. A. Pople, P. C. Redfern, L. A. Curtiss, J. Comput. Chem. 2001, 22, 976-984.

[15] A. D. Becke, J. Chem. Phys. 1993, 98, 5648-5652.

[16] M. J. Frisch et al., Gaussian 09, Revision A.02., Gaussian, Inc., Wallingford CT, 2009. Full text for reference see in Supporting Information.

[17] A. Lembo, P. Tagliatesta, D. M. Guldi, M. Wielopolski, M. Nuccetelli, J. Phys. Chem. A 2009, 113, 1779-1793.

[18] a) T. Clark, J. Mol. Model. 2010, 16, 1231-1238; b) B. Ehresmann, B. Martin, A. H. C. Horn, T. Clark, J. Mol. Model. 2003, 9, 342-347.

[19] T. Clark, J. Lin, A. H. C. Horn, ParaSurf 11, CEPOS Insilico Ltd., Kempston, Bedford, 2011.

[20] a) M. Waldherr-Teschner, T. Goetze, W. Heiden, M. Knoblauch, H. Vollhardt, J. Brickmann in Second Eurographics Workshop on Visualization in Scientific Computing, Delft, 1991; b) J. Brickmann, M. Keil, T. E. Exner, R. Marhöfer, G. Moeckel in The Encyclopedia of Computational Chemistry (Eds.: P. v. R. Schleyer, N. C. Allinger, T. Clark, J. Gasteiger, P. A. Kollmann, H. F. Schaefer, III, P. R. Schreiner), John Wiley \& Sons, Chichester, 1998, pp. 1679-1693; c) J. Brickmann, T. E. Exner, M. Keil, R. J. Marhofer, J. Mol. Model. 2000, 6, 328-340.

[21] J. J. P. Stewart, J. Mol. Model. 2007, 13, 1173-1213. 
[22] T. Clark, A. Alex, B. Beck, F. Burkhardt, J. Chandrasekhar, P. Gedeck, A. Horn, M. Hutter, B. Martin, P. O. Dral, G. Rauhut, W. Sauer, T. Schindler, T. Steinke, VAMP 11.0, University of Erlangen (Germany), 2011.

[23] P. O. Dral, T. Clark, J. Phys. Chem. A 2011, 115, 11303-11312.

[24] a) P. R. T. Schipper, O. V. Gritsenko, S. J. A. v. Gisbergen, E. J. Baerends, J. Chem. Phys. 2000, 112, 1344-1352; b) O. V. Gritsenko, P. R. T. Schipper, E. J. Baerends, Chem. Phys. Lett. 1999, 302, 199207; c) O. V. Gritsenko, P. R. T. Schipper, E. J. Baerends, Int. J. Quantum Chem. 2000, 76, 407-419.

[25] a) Amsterdam Density Functional, ADF 2010.02, SCM, Theoretical Chemistry, Vrije Universiteit, Amsterdam (The Netherlands), 2012, http://www.scm.com; b) G. te Velde, F. M. Bickelhaupt, E. J. Baer- ends, C. F. Guerra, S. J. A. v. Gisbergen, J. G. Snijders, T. Ziegler, J Comput. Chem. 2001, 22, 931-967; c) C. F. Guerra, J. G. Snijders, G. t. Velde, E. J. Baerends, Theor. Chem. Acc. 1998, 99, 391-403.

[26] a) C. C. Pye, T. Ziegler, Theor. Chem. Acc. 1999, 101, 396-408; b) A. Klamt, G. Schüürmann, J. Chem. Soc. Perkin Trans. 2 1993, 799-805; c) A. Klamt, J. Phys. Chem. A 1995, 99, 2224-2235; d) A. Klamt, V. Jonas, J. Chem. Phys. 1996, 105, 9972-9981.

[27] G. Rauhut, T. Clark, T. Steinke, J. Am. Chem. Soc. 1993, 115, 91749181.

[28] Materials Studio v6.0.0, Accelrys Software Inc., 2011.

Received: June 25, 2012 Published online: September 27, 2012 